\title{
Skin and Mucous Membrane Eruptions Associated with Chlamydophila Pneumoniae Respiratory Infections: Literature Review
}

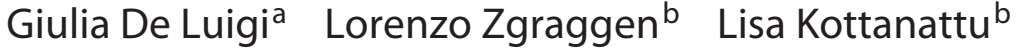 \\ Giacomo D. Simonetti $^{a, b} \quad$ Luisa Terraneo $^{b}$ Federica Vanoni $^{b} \quad$ Isabella Terranic \\ Mario G. Bianchetti ${ }^{a}$ b Sebastiano A.G. Lava ${ }^{d}$ Gregorio P. Milani ${ }^{e, f}$ \\ a Università della Svizzera Italiana, Lugano, Switzerland; b Pediatric Institute of Southern Switzerland, Ospedale San \\ Giovanni, Bellinzona, Switzerland; ' $D$ Department of Dermatology Ente Ospedaliero Cantonale, Ospedale Regionale di \\ Lugano, Lugano, Switzerland; 'P Pediatric Cardiology Unit, Department of Pediatrics, Centre Hospitalier Universitaire

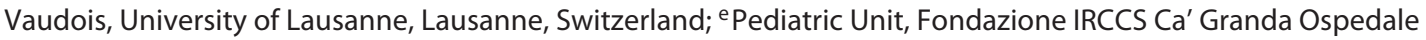 \\ Maggiore Policlinico, Milan, Italy; ${ }^{\mathrm{f}}$ Department of Clinical Sciences and Community Health, Università degli Studi di \\ Milano, Milan, Italy
}

\author{
Keywords \\ Chlamydophila pneumoniae - Erythema multiforme · \\ Erythema nodosum - Cutaneous vasculitis - Respiratory \\ infection · Child
}

\begin{abstract}
Background: Mycoplasma pneumoniae pneumonia is sometimes associated with skin or mucous membrane eruptions. Available reviews do not address the association of Chlamydophila pneumoniae pneumonia with skin eruptions. We therefore conducted a systematic review of the literature addressing this issue. The National Library of Medicine, Excerpta Medica, and Web of Science databases were employed. Summary: In two reports, skin lesions and especially urticaria were more common $(p<0.05)$ in atypical pneumonia caused by $C$. pneumoniae as compared with M. pneumoniae. We found 47 patients ( $<18$ years, $n=16 ; \geq 18$ years, $n=31$ ) affected by a C. pneumoniae atypical pneumonia, which was associated with erythema nodosum, erythema multiforme minus, erythema multiforme majus, isolated mucositis, or cutaneous vasculitis. We also found the case of a boy with $C$. pneumoniae pneumonia and acute generalized exanthema-
\end{abstract}

tous pustulosis. We did not find any case of $C$. pneumoniae respiratory infection associated with either Gianotti-Crosti syndrome, pityriasis lichenoides et varioliformis acuta Mucha-Habermann, or varicella-like skin eruptions.

(c) 2020 S. Karger AG, Basel

\section{Introduction}

Mycoplasma pneumoniae atypical pneumonia is sometimes associated with skin or mucous membrane eruptions [1] such as urticaria and the various forms of erythema multiforme (mostly erythema multiforme majus). More rarely, M. pneumoniae has also been associated with varicella-like skin eruptions, vasculitides such as Henoch-Schönlein syndrome, or erythema nodosum [2].

Chlamydophila pneumoniae, known until recently as Chlamydia pneumoniae, accounts for approximately $10 \%$ of atypical pneumonias [3]. Since available reviews do not address the association of $C$. pneumoniae with skin and mucous membrane eruptions, we reviewed the corresponding literature.

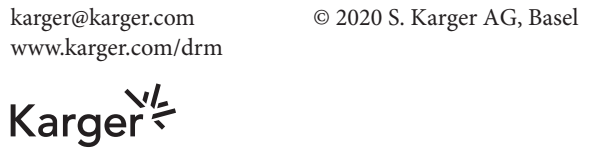

Dr. Sebastiano A.G. Lava, MD MSc

Pediatric Cardiology Unit, Department of Pediatrics Centre Hospitalier Universitaire Vaudois (CHUV)

Rue du Bugnon 46, CH-1011 Lausanne (Switzerland)

webmaster@sebastianolava.ch 
Fig. 1. Non-purulent conjunctivitis, oral mucosal lesions, and penile lesion in a 14-year-old adolescent boy with atypical pneumonia. No skin lesions were noted in the patient. Both the serology and the polymerase chain reaction on sputum were negative for Mycoplasma pneumoniae but were instead found to be positive for Chlamydophila pneumoniae.
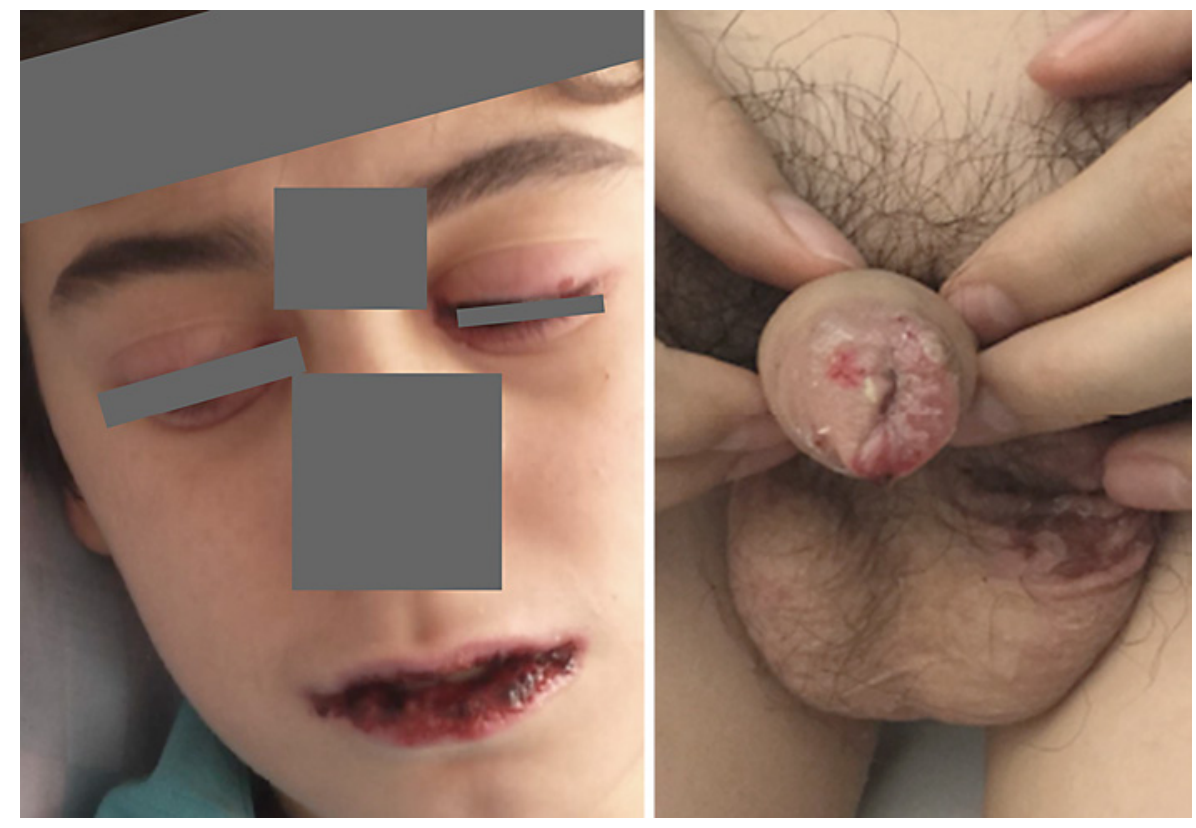

\section{Methods}

\section{Search Strategy: Selection Criteria}

A computer-based search in the National Library of Medicine, Excerpta Medica, and Web of Science databases was performed. The principles advised by the Economic and Social Research Council guidance on the conduct of narrative synthesis and on the Preferred Reporting Items for Meta-Analyses and Systematic Reviews were used [4]. Articles published after 1970 were considered, which address a possible link between C. pneumoniae respiratory infections and erythema multiforme, erythema nodosum, Gianotti-Crosti syndrome, pityriasis lichenoides et varioliformis acuta Mucha-Habermann, urticaria, varicella-like eruptions, and vasculitides with skin involvement. For this purpose, "Chlamydophila pneumoniae" ("Chlamydia pneumoniae") and each of the aforementioned conditions (and their synonyms), skin lesions and eruptions, together with the Boolean operator "AND," were utilized. The literature search was conducted independently by two of the authors (G.D.L. and M.G.B.). Incongruent results were resolved by reaching a consensus. Pertinent secondary references were also screened. Reports published in languages other than Dutch, English, French, German, Italian, Portuguese, or Spanish were excluded.

In the retained cases, the diagnosis of respiratory $C$. pneumoniae infection [3] was based both on characteristic clinical and laboratory features (detection of C. pneu- moniae in a nasopharyngeal swab, a fourfold rise in titer of a specific immunoglobulin $G$ level, a single immunoglobulin $G$ titer $\geq 1: 512$, or a single immunoglobulin $M$ titer $\geq 1: 16)$. Cases with eruptions possibly due both to $C$. pneumoniae as well as to an already recognized cause (e.g., erythema multiforme with clinical and laboratory findings consistent with both $M$. pneumoniae and $C$. pneumoniae infection) were excluded. Cases with possibly drug-induced skin lesions and cases developing in immunodeficient patients were also excluded.

Furthermore, the diagnosis of erythema multiforme (erythema minus, erythema majus, or isolated mucositis), erythema nodosum, Gianotti-Crosti syndrome, pityriasis lichenoides et varioliformis acuta Mucha-Habermann, urticaria, varicella-like eruption, and vasculitides with skin involvement (such as Henoch-Schönlein syndrome) made in the original reports was reviewed using recognized criteria $[2,5]$. Specifically, erythema multiforme was classified as follows: the diagnosis of erythema multiforme minus (or von Hebra syndrome) was made in cases with skin lesions covering 1-10\% of body surface area, target lesions, and inflammation of no more than one mucous membrane, cases of erythema multiforme majus (or Stevens-Johnson syndrome) in patients with skin lesions as in erythema multiforme and inflammation of $\geq 2$ mucus membranes, and cases of isolated mucositis (or Fuchs syndrome; Fig. 1) in patients with inflammation of $\geq 2$ mucus membranes and no skin lesions (or lesions covering $<1 \%$ of body surface area). 


\section{Data Extraction: Analysis}

From each published case, data were sorted using a piloted form and transcribed into a dedicated database. Attempts were also made to contact authors of original articles to confirm the accuracy of reported data or provide additional missing data. The data extracted from each case meeting the study criteria included demographics and both clinical and laboratory data.

Results are presented either as median and interquartile range (which includes half of the data points) or frequency, as appropriate. The Cohen kappa coefficient was used to assess the agreement between investigators. The Fisher test was used to compare dichotomous variables. Statistical significance was assigned at $p<0.05$.

\section{Results}

\section{Search Results}

After reviewing title and abstract, the full text of 41 articles was obtained and assessed in detail (Fig. 2). Ultimately, 26 articles [6-31] published between 1980 and 2019 were retained for analysis: 5 from Japan, 3 from Poland, 3 from Turkey, 3 from the USA, 2 from Spain, 2 from Sweden, and 1 each from the Czech Republic, Finland, France, Italy, Pakistan, Portugal, the UK, and Switzerland. Twenty-three reports were published in English, 2 in French, and 1 in Spanish. The case of a Polish patient with erythema nodosum reported twice $[12,13]$ in the literature was considered only once. The Cohen kappa coefficient between investigators on the application of exclusion and inclusion criteria was 0.93 .

\section{Clinical Data}

General Prevalence of Skin or Mucous Membrane Eruptions

The prevalence of skin lesions was addressed in a case series including 300 Polish children [6] with atypical pneumonia caused by either M. pneumoniae $(n=198)$ or C. pneumoniae $(n=102)$. Skin lesions were observed in 8 (4.5\%) cases with $M$. pneumoniae and $9(8.8 \%$; $p<0.05)$ with $C$. pneumoniae. No further report addressed the prevalence of skin lesions in case series including patients with community-acquired C. pneumoniae atypical pneumonia.

\section{Urticaria}

The existence of a possible association between $C$. pneumoniae and acute urticaria was addressed in 2 reports [7, 8]. In a case series [7], which included 54 paedi-

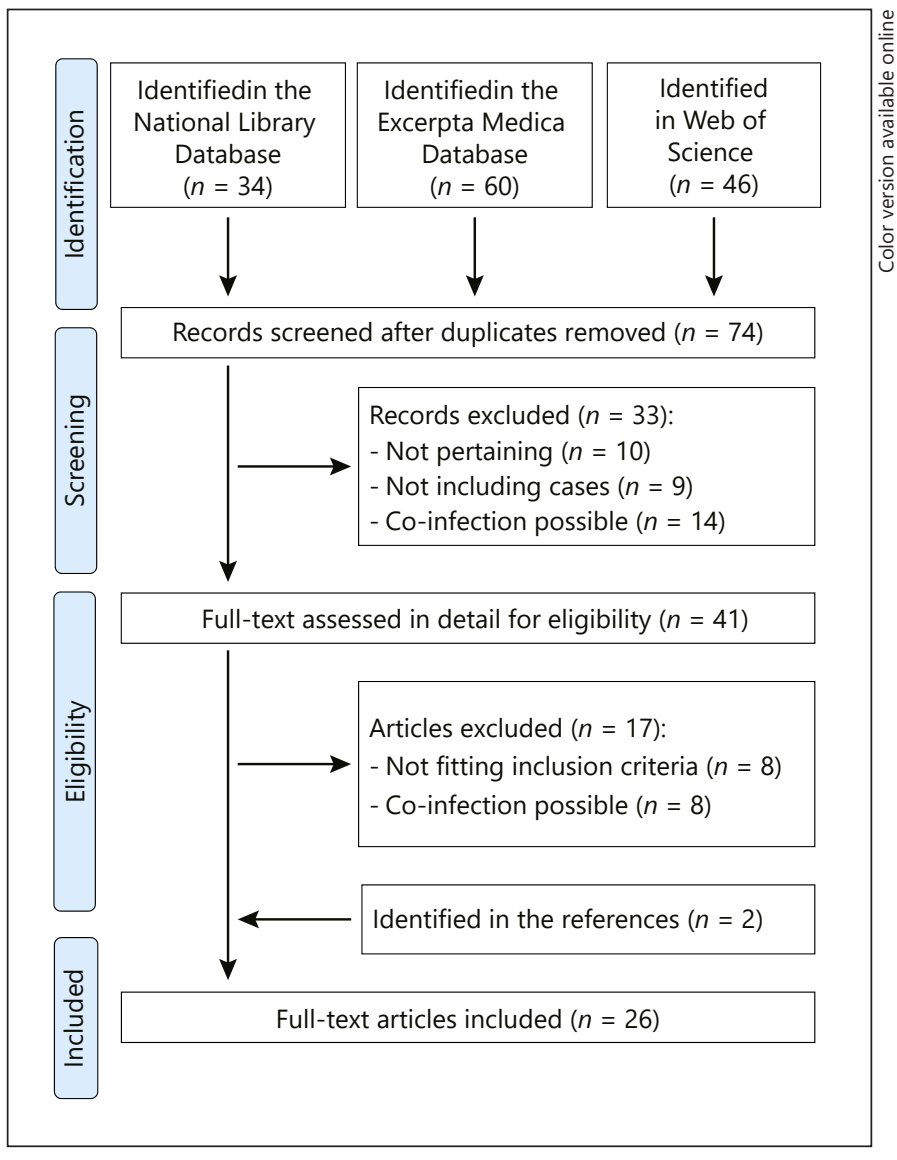

Fig. 2. Skin and mucous membrane eruptions associated with Chlamydophila pneumoniae respiratory infections. Flowchart of the literature search process.

atric patients affected by acute urticaria, the most frequently documented infection was urinary tract infection $(n=7)$, followed by serologically determined infections caused by C. pneumoniae $(n=5)$, Helicobacter pylori $(n=$ 4 ), and M. pneumoniae ( $n=1)$. Furthermore, C. pneumoniae was associated with both a respiratory infection and angioedema in a 13-year-old boy [8].

Erythema Nodosum, Erythema Multiforme, and Vasculitis

In the literature, we found 47 patients [9-22, 24-30] affected by $C$. pneumoniae atypical pneumonia, which was associated with erythema nodosum [9-14], erythema multiforme [15-24] (either erythema multiforme minus, erythema multiforme majus, or isolated mucositis), or cutaneous vasculitis [25-30], as shown in Table 1.

Finally, a retrospective chart review [23] found 9 children with at least three episodes of erythema multiforme or isolated mucositis that were triggered either by $M$. 
Table 1. Characteristics of 47 patients with erythema nodosum, erythema multiforme, or cutaneous vasculitis associated with Chlamydophila pneumoniae pneumonia

\begin{tabular}{|c|c|c|c|c|c|c|}
\hline & \multirow[t]{2}{*}{ All } & \multirow{2}{*}{$\begin{array}{l}\text { Erythema } \\
\text { nodosum }\end{array}$} & \multicolumn{3}{|c|}{ Erythema multiforme } & \multirow{2}{*}{$\begin{array}{l}\text { Cutaneous } \\
\text { vasculitis }\end{array}$} \\
\hline & & & minus & majus & $\begin{array}{l}\text { isolated } \\
\text { mucositis }\end{array}$ & \\
\hline \multicolumn{7}{|l|}{ Age } \\
\hline$<18$ years & 16 & 4 & 6 & 1 & 2 & 2 \\
\hline$\geq 18$ years & 31 & 13 & 11 & 2 & 1 & 5 \\
\hline \multicolumn{7}{|l|}{ Gender } \\
\hline Female & 26 & 10 & 12 & 0 & 0 & 4 \\
\hline Male & 21 & 7 & 5 & 3 & 3 & 3 \\
\hline
\end{tabular}

Data are presented as frequency $(n)$. Erythema multiforme: erythema multiforme minus, erythema multiforme majus (Stevens-Johnson syndrome), or isolated mucositis (Fuchs syndrome). ${ }^{\text {a }}$ Including 3 cases of Henoch-Schönlein syndrome. pneumoniae or, less frequently, C. pneumoniae (testing for herpes simplex virus was negative in these patients).

Further Skin Eruptions

Finally, we found the case of a 14-year-old boy with $C$. pneumoniae pneumonia and acute generalized exanthematous pustulosis [31]. In the literature, we did not find any case of $C$. pneumoniae respiratory infection associated with either Gianotti-Crosti syndrome, pityriasis lichenoides et varioliformis acuta Mucha-Habermann, or varicella-like skin eruptions.

\section{Discussion}

More than 55 years ago [32], it was first speculated that C. pneumoniae might present with skin or mucous membrane lesions. To our knowledge, this is the first comprehensive review addressing a possible relationship between this germ and skin lesions. The results of this review suggest that $C$. pneumoniae, like $M$. pneumoniae, may cause urticaria, erythema nodosum, erythema multiforme minus, erythema multiforme majus, isolated mucositis, and various cutaneous vasculitides $[1,2]$.

The results of 2 studies suggest that skin lesions, and especially urticaria, are more common in atypical pneumonia caused by $C$. pneumoniae as compared with $M$. pneumoniae. These findings deserve further confirmation in future research.

It is hard to prove the existence of a causal relationship between C. pneumoniae (or M. pneumoniae) pneumonia and the occurrence of skin and mucous membrane lesions [1]. With this limitation in mind, two possible mechanisms might underlie the development of these extrapulmonary manifestations $[1,33]$. First, skin lesions might develop directly if $C$. pneumoniae is present at the site of inflammation with local inflammatory cytokines induced by the bacterium playing an important pathogenic role. Second, the bacterium might not be present in the skin, but autoimmunity or formation of immune complexes might play the crucial pathogenic role $[1,33]$. Physicians' everyday experience that antimicrobials do not shorten the course of skin and mucous membrane eruptions associated with atypical pneumonia supports this latter hypothesis [33].

There are limitations and strengths that should be noted when reading this report. The major limitation relates to the fact that it includes data from a small number of communications published after 1970, whose quality of reporting is variable and sometimes poor. Furthermore, available data do not allow to estimate the prevalence of the reported skin lesions in C. pneumoniae pneumonia. Finally, we did not specifically investigate the possible existence of skin and mucous membrane eruptions in patients with pneumonia caused by Chlamydophila psittaci, Coxiella burnetii, Francisella tularensis, or Legionella species. The most relevant strength of the study relates to the comprehensive and exhaustive literature search, aiming at surveying the entire literature on this topic.

\section{Conclusion}

Every fifth atypical pneumonia patient experiences extra-respiratory symptoms or findings such as headache, mental confusion, meningeal signs, or rash [32]. This re- 
view of the literature shows that C. pneumoniae pneumonia can be associated with urticaria, erythema multiforme, erythema nodosum, cutaneous vasculitides, and acute generalized exanthematous pustulosis.

\section{Key Message}

This review of the literature shows that Chlamydophila pneumoniae pneumonia may cause urticaria, erythema multiforme, erythema nodosum, cutaneous vasculitides, and acute generalized exanthematous pustulosis.

\section{Statement of Ethics}

Written consent to publish the photographs was obtained from the patient and his guardians.

\section{Disclosure Statement}

The authors have no conflicts of interest to declare.

\section{Funding Sources}

The research work related to this study did not receive any funding or financial support.

\section{Author Contributions}

Drs. Bianchetti, Lava, and Milani were responsible for the conception and design of the study. Drs. De Luigi and Bianchetti were responsible for literature screening, article selection, and data extraction. Drs. De Luigi, Zgraggen, Kottanattu, Terrani, Vanoni, and Simonetti were responsible for the interpretation of data. Drs. Bianchetti, Lava, and Milani were responsible for statistical analysis. Drs. De Luigi, Bianchetti, Terraneo, and Terrani were responsible for manuscript preparation. Drs. Lava, Milani, and Simonetti critically revised the manuscript. All authors read and approved the final manuscript.

\section{References}

1 Smith LG. Mycoplasma pneumonia and its complications. Infect Dis Clin North Am. 2010 Mar;24(1):57-60.

2 Terraneo L, Lava SA, Camozzi P, Zgraggen L, Simonetti GD, Bianchetti MG, et al. Unusual eruptions associated with Mycoplasma pneumoniae respiratory infections: review of the literature. Dermatology. 2015;231(2):152-7.

3 Burillo A, Bouza E. Chlamydophila pneumoniae. Infect Dis Clin North Am. 2010 Mar; 24(1):61-71.

4 Moher D, Liberati A, Tetzlaff J, Altman DG PRISMA Group. Preferred reporting items for systematic reviews and meta-analyses: the PRISMA statement. Ann Intern Med. 2009 Aug; 151(4):264-9.

5 Lerch M, Mainetti C, Terziroli Beretta-Piccoli B, Harr T. Current perspectives on erythema multiforme. Clin Rev Allergy Immunol. 2018 Feb;54(1):177-84

6 Kicinski P, Wisniewska-Ligier M, Wozniakowska-Gesicka T. Pneumonia caused by Mycoplasma pneumoniae and Chlamydophila pneumoniae in children - comparative analysis of clinical picture. Adv Med Sci. 2011; 56(1):56-63.

7 Sackesen C, Sekerel BE, Orhan F, Kocabas CN, Tuncer A, Adalioglu G. The etiology of different forms of urticaria in childhood. Pediatr Dermatol. 2004 Mar-Apr;21(2): 102-8.

8 Uysal P, Karaman M, Karaman O, Tuncel T, Firınc1 F, Ayyıldız ZA, et al. Chlamydia pneumoniae infection presenting with angioedema in an adolescent. Pediatr Int. 2012 Aug; 54(4):571-2.
9 Kousa M, Saikku P, Kanerva L. Erythema nodosum in chlamydial infections. Acta Derm Venereol. 1980;60(4):319-22.

10 Erntell M, Ljunggren K, Gadd T, Persson K. Erythema nodosum - a manifestation of Chlamydia pneumoniae (strain TWAR) infection. Scand J Infect Dis. 1989;21(6):693-6.

11 Sundelöf B, Gnarpe H, Gnarpe J. An unusual manifestation of Chlamydia pneumoniae infection: meningitis, hepatitis, iritis and atypical erythema nodosum. Scand J Infect Dis. 1993;25(2):259-61.

12 Bergler-Czop B, Lis-Święty A, KamińskaWinciorek G, Brzezińska-Wcisło L. Erythema nodosum caused by ascariasis and Chlamydophila pneumoniae pulmonary infection-a case report. FEMS Immunol Med Microbiol. 2009 Dec;57(3):236-8.

13 Bergler-Czop B, Lis-Święty A, KamińskaWinciorek G, Brzezińska-Wcisło L. Erythema nodosum coexisting with ascariasis and pulmonary Chlamydia pneumoniae infection case report. Postepy Dermatol Allergol. 2009; 36(5):280-3.

14 Düzgöl M, Kara A, Bayram N, Devrim I. Erythema nodosum associated with Chlamydia pneumoniae infection. J Tepecik Educ Res Hosp. 2016;26(2):161-4

15 Saada D, Velasco S, Vabres P, Guillet G. Erythème polymorphe majeur et infection à Chlamydia pneumoniae [Erythema multiforme majus and Chlamydia pneumoniae infection]. Ann Dermatol Venereol. 2006 Dec; 133(12):1001-4. French.

16 Duarte AF, Cruz MJ, Moreira E, Baudrier T, Mota A, Azevedo F. Stevens-Johnson syn- drome/erythema multiforme major and Chlamydia pneumoniae infection in young patients. Dermatol Rep. 2010 Mar;2(1):e6.

17 Hosokawa R, Kobayashi T, Higashino T, Asano C, Ono K, Fujimoto N, et al. Two cases of erythema exsudativum multiforme associated with Chlamydia pneumoniae infection. J Dermatol. 2012 Mar;39(3):306-8.

18 Imashuku S, Kudo N. Chlamydia pneumoniae infection-associated erythema multiforme. Pediatr Rep. 2013 Jun;5(2):35-7.

19 Tanaka A, Nakano M, Tani M, Kira M, Katayama I, Nakagawa J, et al. Adult case of Stevens-Johnson syndrome possibly induced by Chlamydophila pneumoniae infection with severe involvement of bronchial epithelium resulting in constructive respiratory disorder. J Dermatol. 2013 Jun;40(6):492-4.

20 Milner TL, Gomez Mendez LM. StevensJohnson syndrome, mucositis, or something else? Hosp Pediatr. 2014 Jan;4(1):54-7.

21 Sawada T, Suehiro M. Erythema multiforme associated with Chlamydophila pneumoniae infection: a report of two cases and a mini-literature review. J Dermatol. 2015 Mar;42(3):336-7.

22 Mayor-Ibarguren A, Feito-Rodriguez M, González-Ramos J, Del Rosal-Rabes T, González-Sainz FJ, Sánchez-Orta A, et al. Mucositis secondary to Chlamydia pneumoniae infection: expanding the Mycoplasma pneumoniae-induced rash and mucositis concept. Pediatr Dermatol. 2017 Jul;34(4):465-72.

23 Olson D, Abbott J, Lin C, Prok L, Dominguez SR. Characterization of children with recurrent episodes of Stevens-Johnson syndrome. J Pediatric Infect Dis Soc. 2017 Sep;6(3):e140-3. 
24 Umapathi KK, Tuli J, Menon S. Chlamydia pneumonia - induced mucositis. Pediatr Neonatol. 2019 Dec;60(6):697-698.

25 Chakravarty K, Merry P. Systemic vasculitis and atypical infections: report of two cases. Postgrad Med J. 1999 Sep;75(887): 544-6.

26 Cascina A, Marone Bianco A, Mangiarotti P, Montecucco CM, Meloni F. Cutaneous vasculitis and reactive arthritis following respiratory infection due to Chlamydia pneumoniae: report of a case. Clin Exp Rheumatol. 2002 Nov-Dec;20(6):845-7.

27 Beltrán García S, Domínguez Cajal M, Lafuente Hidalgo M, García Sánchez N, Benito Ruesca R. Púrpura de Schönlein-Henoch y Chlamydophila pneumoniae [Henoch-
Schönlein purpura and Chlamydophila pneumoniae]. An Pediatr (Barc). 2008 Feb;68(2): 196-7. Spanish

28 Sakuma H, Niiyama S, Amoh Y, Katsuoka K. Chlamydophila pneumoniae infection induced nodular vasculitis. Case Rep Dermatol. 2011 Sep;3(3):263-7.

29 Majid A. Nodular vasculitis caused by chlamydophila pneumoniae. J Infect Mol Biol. 2013;1(3):49-51.

30 Volejnikova J, Horacek J, Kopriva F. Dapsone treatment is efficient against persistent cutaneous and gastrointestinal symptoms in children with Henoch-Schönlein purpura. Biomed Pap Med Fac Univ Palacky Olomouc Czech Repub. 2018 Jun; 162(2):154-8.
31 Manzano S, Guggisberg D, Hammann C, Laubscher B. Pustulose exanthématique aiguë généralisée: premier cas décrit en relation avec une infection à Chlamydia pneumoniae [Acute generalized exanthematous pustulosis: first case associated with a Chlamydia pneumoniae infection]. Arch Pediatr. 2006 Sep;13(9):1230-2. French.

32 Hellgren L, Hersle K. Acute and chronic urticaria. A statistical investigation on clinical and laboratory data in 1.204 patients and matched healthy controls. Acta Allergol. 1964;19:406-20.

33 Cunha BA, Ortega AM. Atypical pneumonia. Extrapulmonary clues guide the way to diagnosis [Erratum in: Postgrad Med. 1996;99(4]. Postgrad Med. 1996 Jan;99(1):123-8. 